\section{Study of the population dynamics of Listeria monocytogenes and Pseudomonas fluorescens in buffalo mozzarella by means of challenge testing}

\author{
Donatella Nava, ${ }^{1}$ Salvatore Capo, ${ }^{1}$ \\ Vincenzo Caligiuri, ${ }^{1}$ Valerio Giaccone, ${ }^{2}$ \\ Loredana Biondi,' \\ Gerardo Francesco Vaccaro, ${ }^{3}$ \\ Achille Guarino, ${ }^{1}$ Federico Capuano'
}

'Institute for Experimental Veterinary Medicine of Southern Italy, Portici (NA); 2Department of Animal Medicine, University of Padua, Padua;

${ }^{3}$ Local Health Unit - Naples 3 South, Cercola (NA), Italy

\section{Abstract}

Campania's buffalo mozzarella is a greatly appreciated cheese in Italy and worldwide. From a microbiological standpoint, it is a highly perishable food and potentially at risk of contamination by pathogens such as Listeria monocytogenes (L. monocytogenes). The present paper reports the results of a challenge test carried out to assess the population dynamics of $L$. monocytogenes, alone and in presence of Pseudomonas fluorescens (P. fluorescens), in buffalo mozzarella. For this purpose buffalo mozzarella samples were contaminated with $L$. monocytogenes alone or combined with $P$. fluorescens. In samples where $L$. monocytogenes was inoculated alone, the bacterial load remained unchanged. On the contrary, in samples contaminated with $L$. monocytogenes and $P$. fluorescens, the growth of $L$. monocytogenes increased.

\section{Introduction}

Over 1600 types of cheese are produced worIdwide; their characteristics vary according to the geographical area of production and local traditions. Stretched curd cheeses made from buffalo milk are typical products of southern Italy. Amongst these cheeses, the mozzarella di bufala campana (Campania's buffalo mozzarella) takes pride of place. Owing to the production process, this cheese is a highly perishable foodstuff and a possible source of food poisoning.

In recent years, an increase in cases of abnormal coloration of fresh stretched curd cheeses has been reported in Italy (Cantoni $e t$ al., 2003). The cause of these colorations has been attributed to a biovariant of Pseudomonas fluorescens (P. fluorescens) that is able to produce blue pigments (biovar IV). A further characteristic of $P$. fluorescens is its ability to produce biofilm. Listeria monocytogenes (L. monocytogenes), which also produces a biofilm, can exploit the biofilms produced by $P$. fluorescens on work surfaces and on the products themselves, thereby becoming more resistant not only to adverse environmental conditions but also to some of the disinfectants commonly used for environmental sanitation (Saá Ibusquiza et al., 2012; Wuertz et al., 2004; Norwood and Gilmour, 1999, 2001; Pan et al., 2006; Kastbjerg and Gram, 2009). L. monocytogenes is able to survive for long periods in various ecological niches, including work surfaces in stables as well as and in dairy and cheese-making facilities (Porsby et al., 2008).

Human listeriosis is mainly (95-99\%) a foodborne disease (Scallan et al., 2011; Kovacevic et al., 2013). Human infections are caused by ingestion of contaminated foodstuffs, which allow the growth of $L$. monocytogenes. In humans with normal immune defenses the infective dose is believed to be $10^{4}$ colony forming unit (CFU)/g L. monocytogenes, while in immunocompromised subjects it can even be lower than $10^{3} \mathrm{CFU} / \mathrm{g}$ (Ooi and Lorber, 2005). From 2008 to 2011, cases of human listeriosis in Europe remained stable at a rate of about 1400 per year (Denny and McLauchlin, 2008; EFSA, 2013). Over the last 30 years, several outbreaks of food poisoning due to cheeses contaminated by $L$. monocytogenes have been reported (EFSA, 2013). $L$. monocytogenes can survive in substrates containing up to $16 \%$ of salt, and can even double in fresher, less-mature substrates and those containing less salt (Oliver et al., 2009; Fretz et al., 2010).

The aim of the present study was to investigate the growth of $L$. monocytogenes associated to $P$. fluorescens in buffalo mozzarella, by means of a series of assays and experimental inoculations of these two bacteria, alone or in combination

\section{Materials and Methods}

The challenge test was carried out in accordance with a protocol designed by ANSES 2008 guidelines (ANSES, 2008). One hundred and twenty eight mozzarella cheeses were collected, each weighing $100 \mathrm{~g}$ and belonging to a single production batch. The detection of $L$. monocytogenes and the enumeration of $P$. fluorescens were immediately evaluated on samples as reported below. Samples were indivi-
Correspondence: Donatella Nava, Institute for Experimental Veterinary Medicine of Southern Italy, via Salute 2, 80055 Portici (NA), Italy Tel: +39.081 .7865338 - Fax: +39.081 .7865342$

E-mail: donatella.nava@cert.izsmportici.it

Key words: Buffalo mozzarella; Campania; Challenge test; Listeria monocytogenes; Pseudomonas fluorescens.

Conflict of interest: the authors declare no potential conflict of interest.

Received for publication: 18 December 2015 Revision received: 24 March 2016.

Accepted for publication: 27 March 2016.

This work is licensed under a Creative Commons Attribution-NonCommercial 4.0 International License (CC BY-NC 4.0).

CC Copyright D. Nava et al., 2016

Licensee PAGEPress, Italy

Italian Journal of Food Safety 2016; 5:5690

doi:10.4081/ijfs.2016.5690

dually immersed in a conservation liquid inside single packages, then they were contaminated with three different strains of $L$. monocytogenes and three strains of $P$. fluorescens - one standard strain (ATCC 13932) and two wild strains isolated from dairy products [one in the culturable (V) phase, i.e. live and able to replicate, and the other in the viable-but-notculturable (VBNC) phase, i.e. live but unable to replicate]. The contamination was performed by immersion of each sample in solutions of bacteria at room temperature $\left(22 \pm 1^{\circ} \mathrm{C}\right)$ for two min. The bacterial loads of the solutions were 10 and $100 \mathrm{CFU} / \mathrm{mL}$ respectively. After contamination, the samples were stored at a temperature of $4 \pm 1^{\circ} \mathrm{C}$ for the first three days, and were then stored at $12 \pm 1.5^{\circ} \mathrm{C}$ until the end of the experiment (day 11; T11).

The detection of $L$. monocytogenes and enumeration of $L$. monocytogenes and $P$. fluorescens as well as the chemical-physical analyses [ $\mathrm{pH}$ value and water activity $\left(\mathrm{a}_{\mathrm{w}}\right)$ value] were performed after 1, 3, 6, 9 and 11 days of storage (times T1, T3, T6, T9 and T11). Each test was performed in duplicate. For the microbiological assays, the following methods were performed: detection of $L$. monocytogenes by means of the VIDAS $^{\odot}$ (bioMérieux, Marcy l'Etoile, France) technique; $L$. monocytogenes count by means of UNI EN/ISO 11290-2:2005 (ISO, 2005); $P$. fluorescens count by means of ISO/TS 11059 IDF/RM 225:2009 (ISO, 2009). pH and $\mathrm{a}_{\mathrm{w}}$ were detected through the use of pH-meter Knick 911 (Crami Group, Pero, Italy) and Fast-lab (GBX, Dublin, Ireland) devices, according to the manufacturer's instructions. 


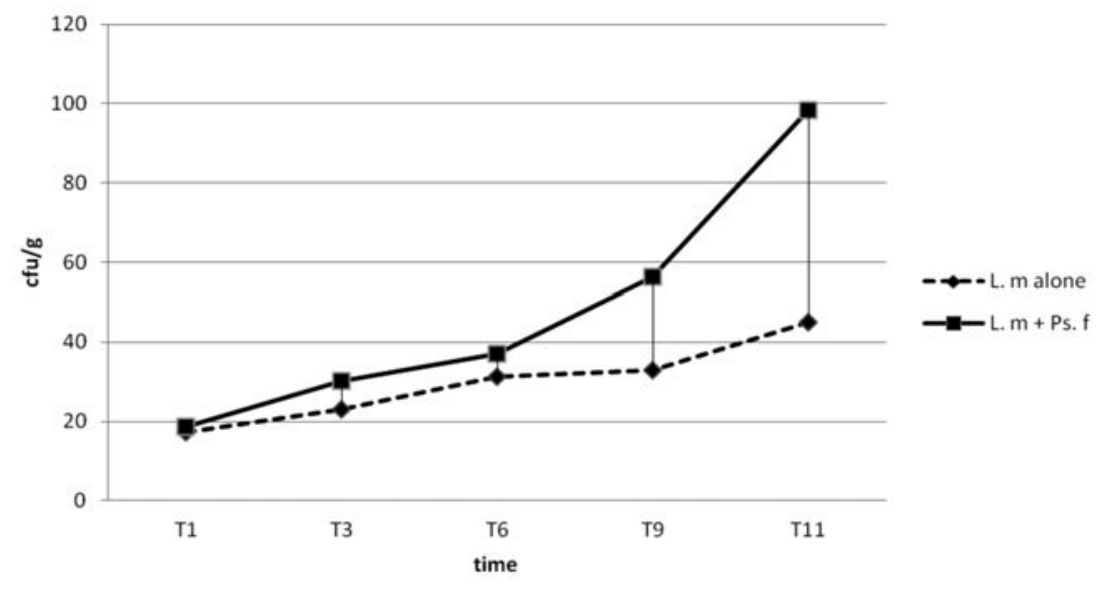

Figure 1. Enumeration of Listeria monocytogenes alone and combined with Pseudomonas fluorescens: average of the results globally observed.

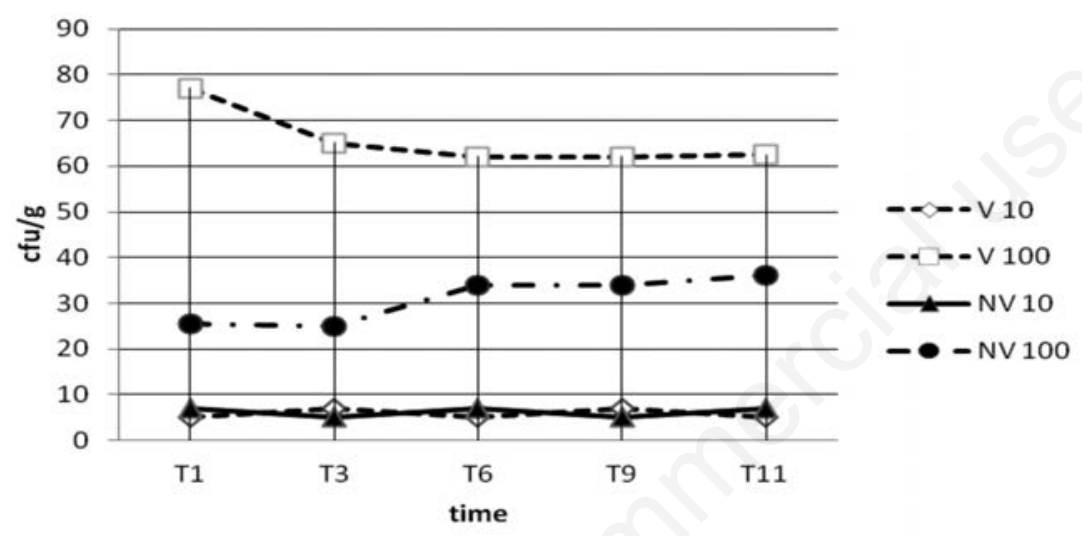

Figure 2. Enumeration of Listeria monocytogenes alone: all types of inoculums. V, culturable; NV, viable-but-not-culturable; 10 and 100, amount of inoculums (colony forming unit).

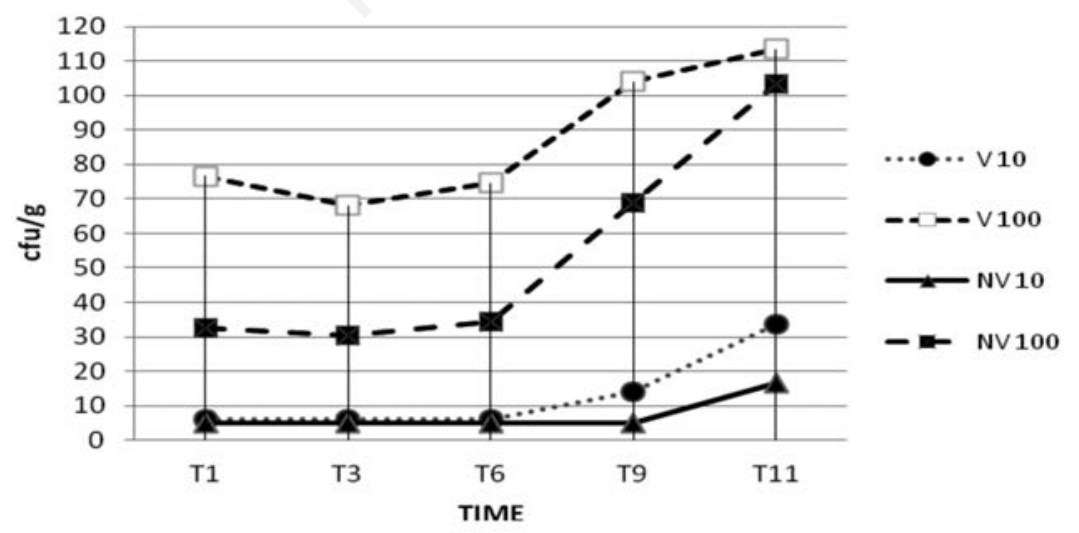

Figure 3. Enumeration of Listeria monocytogenes in samples contaminated jointly with Pseudomonas fluorescens: all types of inoculums. V, culturable; NV, viable-but-not-culturable; 10 and 100, amount of inoculums (colony forming unit).

\section{Results and Discussion}

The results obtained are reported in Figures 1, 2 and 3. L. monocytogenes was detected in all analysed samples, though sometimes at loads below the detection limit of the EN ISO 112902:2005 technique (ISO, 2005). In the samples where $L$. monocytogenes was inoculated alone, the bacterial load of both forms (V and VBNC) remained substantially unchanged (Figure 2). By contrast, in those samples where L. monocytogenes was inoculated jointly with $P$. fluorescens, the growth of the latter influenced the growth of the former (Figure 3). In these last samples, L. monocytogenes growth increased starting from $\mathrm{T} 6$ of the experiment.

None of the samples analysed showed modification in sensory properties or in the occurrence of improper pigmentations related to contamination by $P$. fluorescens. The $\mathrm{pH}$ of the cheeses tested became slightly more acidic, moving from initial values of 5.41 to values of $5.34 \mathrm{pH} \mathrm{U}$ at the end of the $11^{\text {th }}$ day of conservation. Finally, the value of $a_{w}$ in the samples analysed declined slightly, from initial values of 0.983 to final values of 0.978 .

\section{Conclusions}

Campania's buffalo mozzarella is a fresh cheese with a short shelf-life and values of $\mathrm{pH}$ and $\mathrm{a}_{\mathrm{w}}$ which, in theory, are insufficient to curb the growth of a pathogen such as L. monocytogenes. Nevertheless, the results of our tests seem to indicate that the chemical and physical properties of this product, as well as other factors not considered in this study, are able to curb the growth of $L$. monocytogenes, provided that the contaminating bacterial load is low or very low (around $10 \mathrm{CFU} / \mathrm{g}$ or less). The growth of the pathogen remained below 0.5 degrees $\log$ of load between the value estimated on day 1 (T1) and at the end of the test (T11). The growth of $L$. monocytogenes appears to be positively influenced by the co-presence of $P$. fluorescens (Figure 1), thus revealing the role of $P$. fluorescens not only as spoilage bacteria, but also as an indirect source of risk for human beings.

\section{References}

ANSES, 2008. Technical guidance document on shelf-life studies for Listeria monocytogenes in ready-to-eat-foods. Agence Nationale de Sécurité Sanitaire de l'alimentation, de l'environnement et du Travail ed., Maisons-Alfort, France.

Cantoni C, Stella S, Cozzi M, Iacumin L, Comi 
G, 2003. Blue colouring in mozzarella cheese. Ind Aliment 42:840-3.

Denny J, McLauchlin J, 2008. Human Listeria monocytogenes infections in Europe: an opportunity for improved European surveillance. Eurosurveillance 13:8082.

EFSA, 2013. The European Union summary report on trends and sources of zoonoses, zoonotic agents and food-borne outbreaks in 2011. EFSA J 11:3129.

Fretz R, Pichler J, Sagel U, Much P, Ruppitsch W, Pietzka AT, 2010. Update: multinational listeriosis outbreak due to 'Quargel,' a sour milk curd cheese, caused by two different L. monocytogenes serotype 1/2a strains, 2009-2010. Eurosurveillance 15:19543.

ISO, 2005. Microbiology of food and animal feeding stuffs. Horizontal method for the detection and enumeration of Listeria monocytogenes. Part 2: Enumeration method. ISO Norm 11290-2:2005. International Standardization Organization ed., Geneva, Switzerland.

ISO, 2009. Milk and milk products. Method for the enumeration of Pseudomonas spp. ISO Norm 11059:2009 (IDF/RM 225:2009). International Standardization
Organization ed., Geneva, Switzerland. Kastbjerg VG, Gram L, 2009. Model systems allowing quantification of sensitivity to disinfectants and comparison of disinfectant susceptibility of persistent and presumed nonpersistent Listeria monocytogenes. J Appl Microbiol 106:1667-81.

Kovacevic J, Sagert J, Wozniak A, Gilmour MW, Allen KJ, 2013. Antimicrobial resistance and co-selection phenomenon in Listeria spp. recovered from food and food production environments. Food Microbiol 34:319-27.

Norwood D, Gilmour A, 1999. Adherence of Listeria monocytogenes strains to stainless steel coupons. J Appl Microbiol 86:576-82.

Norwood DE, Gilmour A, 2001. The differential adherence capabilities of two Listeria monocytogenes strains in monoculture and multispecies biofilms as a function of temperature. Lett Appl Microbiol 33:320-4.

Oliver SP, Boor KJ, Murphy SC, Murinda SE, 2009. Food safety hazards associated with consumption of raw milk. Foodborne Pathog Dis 6:793-806.

0oi ST, Lorber B, 2005. Gastroenteritis due to Listeria monocytogenes. Clin Infect Dis 40:1327-32.
Pan Y, Breidt F Jr, Kathariou S, 2006. Resistance of Listeria monocytogenes biofilms to sanitizing agents in a simulated food processing environment. Appl Environ Microb 72:7711-7.

Porsby CH, Vogel BF, Mohr M, Gram L, 2008. Influence of processing steps in cold-smoked salmon production on survival and growth of persistent and presumed nonpersistent Listeria monocytogenes. Int J Food Microbiol 122:287-95.

Saá Ibusquiza P, Herrera JJR, VázquezSánchez D, Cabo ML, 2012. Adherence kinetics, resistance to benzalkonium chloride and microscopic analysis of mixed biofilms formed by Listeria monocytogenes and Pseudomonas putida. Food Control 25:202-10.

Scallan E, Hoekstra RM, Angulo FJ, Tauxe RV, Widdowson MA, Roy SL, Jones JL, Griffin PM, 2011. Foodborne illness acquired in the United States major pathogens. Emerg Infect Dis 17:7-15.

Wuertz S, Okabe S, Hausner M, 2004. Microbial communities and their interactions in biofilm systems: an overview. Water Sci Technol 49:327-36. 